\title{
Making sense of race/ethnicity and gender in televised football: reception research among British students
}

\section{Rens Peeters \& Jacco van Sterkenburg}

To cite this article: Rens Peeters \& Jacco van Sterkenburg (2017) Making sense of race/ethnicity and gender in televised football: reception research among British students, Sport in Society, 20:5-6, 701-715, DOI: 10.1080/17430437.2016.1158472

To link to this article: https://doi.org/10.1080/17430437.2016.1158472
(2) 2016 The Author(s). Published by Informa UK Limited, trading as Taylor \& Francis Group

\section{Published online: 17 Mar 2016.}

Submit your article to this journal $\pi$

Џ Article views: 580

Q View related articles $\longleftarrow$

\section{View Crossmark data \lceil}




\title{
Making sense of race/ethnicity and gender in televised football: reception research among British students*
}

\author{
Rens Peeters and Jacco van Sterkenburg \\ Erasmus Research Centre for Media, Communication and Culture, Erasmus University, Rotterdam, The \\ Netherlands
}

\begin{abstract}
Most people today watch football by way of the mass media, sites that reproduce and transform ideologies and ideas surrounding racial/ ethnic and gender identity. However, still little remains known as to what extent actual football viewers take up or resist these ideas. Drawing on a cultural studies perspective, this study tries to identify the dominant discourses that British television viewers use to assign meaning to race/ethnicity and gender in men's and women's football on television. Eleven focus groups of British students $(n=44)$ were utilized to explore these discourses. Our findings indicate that viewers from various ethnic backgrounds were largely compliant with the hegemonic media discourses about natural physicality in both gender and race/ethnic comparisons. At the same time, multiple negotiated/ oppositional discourses were found in relation to women's football that showed how other social practices contributed to such readings. Limitations and possible areas for future research are discussed.
\end{abstract}

\section{Introduction and aim}

Football on television has become one of the most popular forms of entertainment and a primary form of leisure for many people. This also applies to the English context where football constitutes an important part of the nation's cultural identity (Lines 2000). Huge events such as EURO 2012 or the 2014 FIFA World Cup draw millions of viewers and football matches consistently are among the best watched programmes on British television (Conlan 2012). Televised football, by virtue of its massive popularity, functions as a key site where prominent ideas about identity groupings such as nationality, race/ethnicity, gender and sexuality and the differences they entail are reproduced and naturalized. In a multicultural society that has openly began to question the apparent lack of Englishness of its highest national football league with the influx of foreign players, managers and owners (Gibson 2013), the question of how dominant ideas about race and ethnicity inside the 
football media are related to and understood by the television audience becomes all the more relevant. A similar question regarding gender should be pursued, as women have in increasing numbers made their way into the football stadiums, as audiences and as players, making it the most practiced team sport among women in the UK (Women's Sport and Fitness Foundation's 2012).

In the last two decades, textual and content analyses of gender and race/ethnicity representations in the sports media have uncovered a number of transnational trends that are remarkably persistent over time. Although improvements have been visible, sportswomen (especially those performing in sports that are traditionally geared towards men) remain underrepresented in terms of media coverage when compared to sportsmen (Adams et al. 2014). Furthermore, women are often represented in stereotypical ways that trivialize and marginalize their athletic performances and instead focus on their femininity and heterosexuality (Bruce 2013; Pressland 2012). Research has also shown that sport and football commentators (unconsciously) employ racial/ethnic stereotypes (Hylton 2009; McCarthy, Jones, and Potrac 2003), thereby reinforcing long-standing ideas about the natural athletic black body and white cognitive capabilities (Carrington and McDonald 2001).

While these content and textual analyses have certainly provided valuable insights into the discourses provided by the sports and football media, they fail to provide concrete information on the way different audiences receive and interpret these texts. Audience research that investigates the discourses employed by consumers of sport media remains relatively scarce (Bruce 2013; Cooky, Messner, and Hextrum 2013). This is surprising since media scholars agree that media texts acquire meaning in the complex interactions between those texts and their viewers/readers (Hermes 2005). It is of the essence, therefore, to start doing audience reception research. In the present study, we will therefore address the sport media audience and explore:

(1) The discourses television viewers of various ethnic and gender groupings draw on to give meaning to race/ethnicity and gender in men's and women's football.

(2) How viewers' individual receptions and discourses overlap with hegemonic media discourses and strengthen or challenge wider hegemonic discourses and relations of power in multi-ethnic society.

\section{State of knowledge and research question}

The few studies that have been conducted in this field show that media consumers don't necessarily comply with the stereotypical representations of ethnic or gender groupings or that they are at least more complex than textual analysis suggests. A study by McCarthy, Jones, and Potrac (2003) shows, for example, how black British viewers frequently rejected stereotypical comments directed at black players by sport commentators. In a similar vein, Knoppers and Elling (2001) reported that immigrants in the Netherlands tend to oppose dominant representations regarding race and ethnicity in the sport media more often than non-immigrants. Regarding the latter finding, several studies from different countries have indicated that white media users more readily employ stereotypical explanations (natural physicality) regarding black athletic performances (Harrison, Lawrence, and Bukstein 2011; Morning 2009).

Regarding the differences between male and female athletes, both men and women are more eager to employ the hegemonic media discourse which emphasizes that men are naturally 
stronger and tougher than women (Knoppers and Elling 2001; Lines 2000). Even though the media construct men's sport as the norm, viewers do have the capacity to reject this marginalization of women's sport and actively enjoy it, as, for example, Bruce has shown in the case of US women's basketball (Bruce 1998). A recent body of research has furthermore shown that consumers of sport generally prefer to view images of physically able sportswomen, instead of the sexualized representations that permeate the sport media (Kane, LaVoi, and Fink 2013).

While these studies provide useful insights, most of them were conducted in the US context, focussed on either race/ethnicity or gender and examined either men's or women's sport. The present study, on the other hand, aimed to gain more insight into the way British television viewers from different ethnic and gender groupings receive and make sense of race/ethnicity and gender representations in men's as well as women's televised football. The question of relevance that we will address can now be formulated as follows: How do English viewers of various racial/ethnic and gender groupings receive and negotiate representations of race/ethnicity and gender in televised men's and women's football?

The point of reference in the present study is the English context. The English context can be considered exemplary for some other European countries such as the Netherlands and France in harbouring a mixture of postcolonial migrants and labour migrants. In addition, football consumption constitutes a significant part of the English cultural identity. This also applies to many other countries across Europe and worldwide (Alabarces, Tomlinson, and Young 2001; Lechner 2007). Results are, therefore, not only relevant for the English context but also for other (Western) European countries where similar trends in football media discourses surrounding race/ethnicity and gender are visible as the ones reported here (De Bruycker 2012; Ličen and Billings 2013). We will draw on a cultural studies perspective to further interpret and discuss the hegemonic discourses that the British television viewers in this study used to assign meaning to race/ethnicity and gender in televised football.

\section{A cultural studies approach}

Working from a cultural studies perspective, televised sport is understood as a site where discourses concerning race/ethnicity and gender are (re)produced and transformed. Following Hall (1995), the concept of discourse is conceptualized here as a way to construct knowledge about a certain topic (such as race or gender) that opens up and at the same time limits the possible ways to talk about a topic. Discourse then, by producing meaningful knowledge about a subject and having real effects on the social world, is always imbued with power relations (Hall 1995). Hegemonic discourses produced inside the sport media often tend to reinforce the status and position of those in powerful positions which leads Bruce to argue that the sport media 'produces coverage by men, for men and about men' $(2013,28)$.

The concepts of race and gender are viewed as dynamic social constructs that acquire meaning in and through discourse (Hall 1995; Pfister 2010). However, these terms are often essentialized in society and the sport media by constructing them as a set of binary oppositions (black/white, masculinity/femininity, etc.) whereby difference is fixed and the status quo retained (Hall 1997). But meanings over these terms are always being contested and hegemony is never completely won. The football media is one of the places where such struggles over meaning takes place. Watching televised football means watching filtered representations that audiences can actively use to make sense of the world, themselves and others (Hall 2011). We don't hold the view that the sport media is the only site from where 
people receive ideas about identity and difference, but, as Carrington has noted (Carrington 2011), it is one of the most powerful social institutions through which popular ideas about race are dispersed. Similarly, the arena of sports is one of the very few places in our modern society where segregation along gender lines is still enacted (Pfister 2010).

Viewers are perceived as active in their negotiation with the meanings of the text, but they're limited by the text at the same time, as the text constructs the subject positions viewers can occupy. Reiterating the earlier argument by Bruce (2013), white males are most ideally suited to take up the ideal subject position and read the text according to its preferred reading (Hall 1980). Marginalized groups may instead more often opt to utilize an oppositional or negotiated reading whereby they either reject the dominant discourse or find some middle ground that incorporates both preferred and oppositional elements (Hall 1980).

\section{Methodology}

\section{Conceptualizing race/ethnicity}

As has been discussed in earlier studies, the conceptualization of race/ethnicity constitutes a methodological challenge in empirical research (e.g. Gunaratnam 2003; McCarthy, Jones, and Potrac 2003). We used the discourse of the black-white binary to both label the respondents and structure most of the questions. Although we realize that the categories of 'black' and 'white' are generalizations lumping together various more specific racial/ ethnic groups, this black-white dualism is still very much alive among the general public in everyday British society (Billings and Hundley 2010; McCarthy, Jones, and Potrac 2003; Schönwälder 2010). This was also apparent in the way respondents in our study described themselves, often invoking white-British or black-British. In addition, the use of this binary provided the opportunity to compare our findings with previous studies which generally used a black-white dichotomy to define race as well. In addition to the black-white binary, the respondents had the opportunity to also use and/or discuss other racial/ethnic categories such as the category of Asian footballers which the respondents regularly referred to (see 'Results' section).

\section{Data collection}

Data have been gathered through a series of focus group interviews. These interviews were conducted with students at Brunel University and Croydon College (both Greater London) in October 2012. We used focus groups because they reflect as closely as possible the everyday TV talk about football as a site of social interaction where meaning is constructed collectively immediately after the broadcast. Of the 44 young people who participated, 29 were females and 15 were males, while there were slightly more students with a black-British (23) than with a white-British (21) background. Each focus group consisted of 3-5 students. These focus groups occasionally consisted of friends resulting in ethnic and gender homogeneous as well as heterogeneous groups. Ages of respondents ranged from 15 to $22 .^{2}$ Viewing behaviour was generally consistent across the focus groups which included many heavy viewers (i.e. watching football every week). Interviews generally lasted somewhere between 40 and $80 \mathrm{~min}$. The interviews were conducted using a semi-structured interview 
which included predetermined topics based on the available body of literature. This provided the necessary amount of focus, but still left room for additional themes to emerge. The interviews were structured around the following main themes: (1) context of (televised) football involvement, (2) discourses surrounding race/ethnicity and gender in televised football, and (3) perceptions towards the football media's treatment of race and gender.

\section{Data analysis}

The analysis undertaken here borrows insights from the grounded theory approach where data give rise to theory (Boeije 2010). A software package was used for the qualitative analysis of the 11 interviews. The first stage of the analysis, using a process of open coding, consisted of identifying themes at the smallest level and concretizing them into comprehensive labels (Strauss and Corbin 1998). Labels that were similar were grouped together in broader categories in the process of axial coding (Strauss and Corbin 1998). We also checked whether the so-formed categories still represented their labels well or that new categories should be created. A third and final step was the integration and refinement of existing categories in a process called selective coding (Strauss and Corbin 1998). The approach required the ability to reverse between steps and question or alter earlier decisions as new themes or concepts emerged from the data.

\section{Results: ethnicity, gender and media commentary}

In this section, we identify and categorize the most prominent discourses used by the respondents to give meaning to race/ethnicity and gender in televised men's and women's football. They are structured around the three themes (ethnicity, gender and media commentary) that were dominant in the interviews.

\section{Ethnicity}

\section{Natural physicality discourse}

Irrespective of their ethnicity or gender, a majority of the respondents used a 'natural physicality discourse ${ }^{1}$ to evaluate black players and differentiate them from other ethnicities. Some respondents used this discourse to explain the apparent over-representation of black players in attacking and winger positions. Black players were often seen as possessing a strong physique and being naturally fast:

[...] but the black people are more often the ones with the power and the speed in order to like progress up the pitch. [...]. They've got the quick feet, they've got like the speed to get in behind the back four and I think you do see that an awful lot.

The natural physicality discourse was refuted by some of the respondents. Two groups (ethnically and gender diverse) did so explicitly. One male participant remarked: 'I think it has been a big thing for a long time, like about black players have supposedly a genetic advantage of being quick. I think that stereotype just carries'. This stereotype is so ingrained in modern football that it has a major influence on where players are positioned on the pitch, one group argued. Besides, this stereotype wouldn't hold up on closer inspection as most black players wouldn't conform to this stereotype of being big and physical. Other respondents believed that a correlation between positions on the pitch and ethnicity was 
no longer valid or would over time disappear. White or Asian players were almost never described in terms of a natural physique.

\section{Mental discourses}

A second, less prevalent, discourse that was used in some groups involved the evaluation of players on the basis of mental capacities. In a few instances, this discourse was linked to the positions taken up in the field by players of different ethnic backgrounds. Several respondents drew on a discourse to positively assess the mentality of white players. First, white players were described in terms of having a good 'perception' or overall view of the pitch:

Paul Scholes he is always vision and what he can do with the ball, like the way he spreads the ball across 60 yard passes. Those are the same with Rooney as well.

These players were furthermore deemed to be role models that put the team above anything else and have good tactical knowledge. A few black male students thought that this tactical knowledge could be the reason for the apparent over-representation of white players in the controlling positions of the game, such as central midfield or central backs. These same students argued that black players play in attacking positions because they want to be 'the star of the show', and the people who get in the limelight are usually the one's that make the goals.

Nonetheless, there were some students that used a mental discourse to ascribe black players with positive mental traits such as hard work or leadership qualities. A white female student argued:

The people that are not English put a hell of a lot more effort into the game, because they actually want to be there. [...]. So if you think Drogba, he sends pretty much half of his wages back to his country, to help them out.

\section{Cultural discourses}

The under-representation of Asians in English football was largely explained through the use of a discourse that referred to 'culture'. Asians, by which respondents usually meant people from Indian or Pakistani origin, were seen as not being interested that much in football, but more invested in a sport like cricket. A statement made by a black male student was exemplary for this discourse: 'So, when Indian families come over to England ... even if the child grows up in England, they're going to play cricket. Because that's what their parents or the whole family has been into'. Other arguments included the lack of Asian role-models, the time devoted to religious activity rather than sports and the claim that English scouts didn't scout for Asian players, either because the Asians play in little known separate leagues or because the scouts harboured stereotypical prejudices which say that Asian people are not very well fit for football.

\section{Gender}

\section{Physicality and mentality discourse}

Although it's difficult to single out a dominant discourse regarding gender, a slight majority tended to view football as a masculine activity. Irrespective of their outlook on football, most students agreed that men are inherently stronger than women. Most respondents believed this to be the main reason that mixed gender teams will probably never happen as the physical difference between men and women is just too large. An argument by a black 
male student further illustrated this: 'You know, the males [...] their bodies are stronger. The female's legs will get broken, if men never held back when they're playing each other'. Some respondents said that mixed teams would ruin football (as a physical contact sport) and argued that physical contact between men and women wasn't desirable.

There existed a different discourse that was, with a few exceptions, primarily used by female students to argue that mixed teams would be interesting in that they would improve the quality of the female players by increasing the competitiveness of the game. Some respondents steered towards mental differences between men and women as a reason why football is masculine. One white male respondent observed: 'Whereas females still have that [...]. When you are older you have that maternal instinct, so you don't want to hurt anyone'. One male student stated he didn't 'expect a woman to be aggressive' as opposed to men.

\section{Entertainment discourses}

A slight majority, a group comprised mostly of male students, found men's football to be more entertaining than women's football, because of its superior quality. Men's football is viewed as being better and more exciting when compared to women's football where 'the quality of the football is not as good as in the men's game'. Respondents argued that women's football has a slower pace, is less technical and players aren't as skilful as their male counterparts. Some respondents found it boring, while others went further as the following comment from a black male student illustrates: '[...] they're [women] not really meant to play. They're not skilled enough'. The students that used this discourse would only watch women's football if it was entertaining enough, meaning that the female players should possess the same qualities that are displayed in the men's game.

By contrast, a slightly smaller group that largely consisted of female students (and some black-British males) also explicitly connected men's football to entertainment, but insisted that this wasn't necessarily a positive thing. This reasoning is explained by one female student who pointed out that men's football is 'all about the media' and that women's football is actually 'all about the football'. Male footballers were deemed to 'play up to the cameras' and when fouled, they would make a fuss about it. On the other hand, women's football was viewed as containing a lot less drama. When a female player gets fouled, she would be 'up and ready to go again' making the game 'flow more'.

\section{Cultural and economic discourses}

In some cases, discourses were used that revolve around 'culture' or 'economy' to explain why women's football has a hard time gaining ground. An 'economic' discourse, used by men and women, was connected to the absence of sponsors and the little amount of funding. Consequently, women do not have the best facilities to train or play. An example was given by a female student who discussed the Arsenal women's team that can't play in the Arsenal stadium. Another aspect that was mentioned was that most of the female players have normal jobs as they don't get paid enough to rely solely on their income from football activities. A cultural discourse focused on the way males got more opportunities to play football from a young age onwards as structured in society's institutions and societal norms and values. A female student remarked: 'Boys do their sports, girl do their sports. So, it is kind of how you are brought up in education'. 


\section{Media commentary}

\section{Masculinity discourse}

All respondents, irrespective of their gender or race, acknowledged that women's football gets less coverage than men's football and that only major international and cup final games are shown on television. When women's football is on television, there's hardly any advertising to promote the game and it's broadcast on more obscure channels. The dominant discourse here is that men's football is the norm in the media. A black-British female claimed that in general 'women aren't portrayed in the media as doing sport'. Male and female respondents also stated that the commentary in a female match was often less exciting and that commentators were less critical on mistakes made by female players and thus don't take women's football as serious. One black-British male described this as follows:

It seems that sometimes commentators, they don't take the women's game as serious when they're commentating. So it's kind of 'aaah she made a mistake,' [...] It's not the same commentating, it's completely different.

This prioritization of men in the media was also witnessed by male and female students in the case of the Sky Sports commentator Andy Gray who made sexist remarks about a female linesman. ${ }^{3}$

Nearly, all groups agreed that women's football could and should get a lot more coverage and that this could increase its popularity. A few male respondents digressed from this by stating that female football just isn't a viable commodity and that more coverage won't change that. This tied in with the more widely accepted idea among respondents that football in the present day is first and foremost a money-making business which is promoted by the media and advertising.

\section{Neutrality discourse}

The vast majority of respondents claimed that commentators do not differentiate between players of different racial/ethnic backgrounds. In most groups, the argument was posited that commentators reflect on what happens on the pitch and that ethnicity isn't a focal point. As a white British woman noted: 'I think mainly during commentating it all focuses on individual players' performance, rather than where that player comes from'. In two groups, this seeming neutrality of commentators was explained by arguing that commentators would be prone to a backlash in the media if they made remarks about someone's race or ethnicity.

An oppositional discourse was identified and used to argue that the media do indeed stereotype players based on their ethnic or racial background. This discourse highlighted the fact the media would associate black players with physical qualities and white players with technical abilities. This claim was on some occasions followed by the argument that these kinds of observations do have some basis in reality, but are usually put forward as 'massive blanket statements', as one black participant notes.

\section{Discussion: hegemonic discourses and contradictions}

This segment shows to what extent discourses used by students to evaluate gender and racial/ ethnic differences in football overlap with hegemonic media discourses. Results are also contextualized by comparing them with findings from earlier studies. As it is impossible to 
exhaust the whole set of data, the focus will be on hegemonic discourses found in the data including their contradictions.

\section{Confirming the dominant}

Regardless of gender or race, a majority of the students used a natural physicality discourse to evaluate black football players. In just a few cases where a possible explanation was given to account for this natural physique, respondents usually pointed to a perceived genetic advantage among black people. This discourse was almost never invoked when the students talked about white or Asian players. White players were more readily connected with positive mental capabilities, although this discourse was less prevalent. Positive capabilities ascribed to white players included a good tactical overview of the pitch, but also terms like teamwork and role model were used. These results are in line with the dominant media discourse whereby black athletes are represented as being naturally gifted athletes, while white athletes are more easily associated with mental and intellectual capabilities (Coakley 2009; Hylton 2009). The relative lack of British Asian players in the English Premier League and the national team was largely explained by reference to cultural inhibitions on the side of Asians. Students stated that Asians either don't play football as they're more invested in a game like cricket, or that they don't do sport at all as they have to attend to religious or educational activities.

Burdsey (2006) shows it is only in the British Asian press that serious coverage is produced, while the mainstream British press usually resorts to irrelevant or 'humourous' coverage that fails to seriously acknowledge the participation of British Asians in the game. Tactics like these produce the effect that British Asians in the game fall outside the scope of the white normative codes inherent in the coverage (Burdsey 2006). White normativity is often silently sustained and normalized through the social construction of whiteness, a set of discourses that produces a privileged and unmarked (i.e. being exempt from race) position from which one can view the world (Hylton 2009). British Asians deviate from this normative standpoint and are either stereotyped and viewed as the other or are completely exempt from the coverage.

A natural physicality discourse was more pronounced in the case of gender, where the majority of students use this discourse to explain the present structuring in football along gender lines. Students that used this discourse construct masculinity with concepts like having a killer mentality and physical presence. Here, an idea of femininity was constructed in the opposite sense and connected with terms pertaining to a maternal instinct and emotional fragility. This natural physicality discourse corresponds with the one practised inside the masculine domain of the sport media where femininity and masculinity are still being constructed along the lines of traditional gender values (Bruce 2013). Many male respondents also used discourses that are congruent with the hegemonic media discourse which constructs male football as the norm and imbues male events with dramatic narratives that acquire a near historical significance (Bruce 2013; Coakley 2009). The fact that football is already structured along gender lines - with a separation between men's football and women's football - might have contributed to the arguments presented by the respondents. Van Dijk has given an account of how social situations (or social contexts) can influence discourse (van Dijk 2009). Likewise, it is also argued that existing gendered structures of professional sport may influence the discourses about gender that media users draw on. 


\section{Alternative discourses and internal inconsistencies}

The entertainment discourse was, however, also used in a non-hegemonic manner by a group of female students and a few (mostly black-British) male students. Some of these students enjoyed women's football or actually preferred it over men's football. Their approach to football is different than the hegemonic media discourse that aligns football with masculinity (Caudwell 2011). While some of them still believed that men are inherently stronger than women, those who opposed this also recognized the role the media play in constituting this difference by presenting stereotypical ideas about men and women.

Little research is available on how viewers (men and women) interpret women's sport on television, but a study conducted by Bruce (1998) on how women receive representations of US women's basketball does provide a useful comparison. Bruce reports that women took the coverage of the men's game as the norm to make comparisons with the coverage of the women's game (Bruce 1998). They acknowledged that the men's game was a higher valued commodity which in turn framed their expectations of the women's game (Bruce 1998). Students in the present study also argued that the commentary in the women's game is less exciting than it is in the men's game and that coverage of women's football is very different in this respect. Instances of sexualization and trivialization are also commented upon in other groups, coinciding with the discourses identified by Bruce (1998). Students argued that women are either portrayed as wives or mothers and in another group the incident with commentator Andy Gray is put forward as an example of sexism in the media. Students identified the discourses of trivialization and ambivalent representation of female athletes that textual analyses have found, but also show how these can be challenged (Cooky, Messner, and Hextrum 2013; Pressland 2012).

Receiving any form of pleasure from watching a women's football match requires a constant act of negotiation, as preferred meanings that are encoded as such by the media need to be read and reconstructed in an alternative way (Bruce 1998; Hall 1980). Even tuning in to a women's game requires effort as games aren't always announced beforehand or are broadcast on the more obscure channels (Bruce 1998). It's also worth noting that the students who adopt this discourse generally tend to watch much football and some of them played football themselves, as knowledge and experience are considered important parameters in the way viewers read a cultural text (Morley 1980, 1983). Discourses at the disposal of the students might also explain why it's mostly black males that used this specific discourse, because members of minority groups in general are more likely to read dominant texts against the grain (Bruce 1998). In one particular group, this explanation is further reinforced by oppositional readings that call out the media on racial stereotyping.

A couple of male students (with diverse ethnic backgrounds) acknowledged that women's football can be of a good standard and some resorted to the statement that gender doesn't matter. Women's football, it was argued, should receive more attention in the media. Although it might be interpreted as a positive view on the behalf of women's football, these students did eventually fall back on stereotypical views of men and women. Thus, statements such as 'gender doesn't matter' imply a negation of difference and at the same time conflict with the stereotypes used to explain differences between men and women. Such ostensible gender neutrality among males can instead be argued to be a form of gender-blindness (Bruce 2011). Furthermore, these explanations lay bare the inherent contradictory nature of discourses (Morley 1980). 
Nonetheless, the much heard argument among women as well as men that women's football should receive more coverage to increase its popularity and the fact that some women as well as men already actively enjoy women's football or even prefer it above men's football, warrants further exploration (Kane 2013). Almost all students were well aware of the fact that sport is a major business and that the media play an integral part in creating or denying opportunities for athletes. While some of these students were thus able to articulate a more comprehensive account of the sport media by seeing how this business model could lead to specific and stereotypical approaches to, for example, women's football, others only acknowledged this point without any further reasoning as to what this actually implied.

An even greater incongruity exists between the hegemonic discourses used by students to evaluate race/ethnicity and the discourses used to evaluate the commentary. Those who were prone to stereotypical approaches to race and ethnicity generally argued that the football commentary is neutral on the topic of race. If pressed a bit further on the topic, some students did acknowledge stereotypes might happen once or twice. Such reasoning was sometimes accompanied with the argument that commentators merely reflect reality and state facts about players. The study by McCarthy, Jones, and Potrac (2003) identified this same ambivalence from the part of white respondents about the use of racial stereotypes in football commentary, stating that 'for the white respondents in this study, only a small discursive space existed between awareness of the black athletic stereotype and acceptance of that stereotype' (McCarthy, Jones, and Potrac 2003).

Skin colour is often deemed insignificant, a non-issue, in light of a player's (or team's) overall quality and skill. This particular account might be indicative of what has been termed 'colour-blind racism' (Bonilla-Silva and Dietrich 2011), an ideology that sees racism and racial stereotyping as something of the past and no longer an issue even though a great variety of studies proof otherwise. Colour-blind racism operates through the denial of the structural character of racism and thereby leaves unequal power relations, white normativity and the invisibility of whiteness unmarked and unspoken (Bonilla-Silva and Dietrich 2011; Hylton 2009). Colour-blind racism was also evident in the statements by respondents who claimed on the one hand that race or ethnicity has nothing to do with how players play while associating, on the other hand, black players with natural physicality and white players with mentality. Again, it shows the contradictory character of discourses that are being used which was also evident in the finding that some black and white students identified and opposed racial stereotypes that circulate in the media and that also persist in sport itself as expressed through trainers and scouts. These findings corroborate those of Cleland and Cashmore who report how this colour-blind ideology remains embedded in football authorities and how sometimes fans are very much aware of the persistent nature of racism in contemporary football (Cleland and Cashmore 2013).

\section{Conclusion}

Our findings show that ideas about the natural physicality of the black football player remain firmly embedded in the minds of sport media audiences. This discourse was often complemented with the discourse of colour-blindness which discards racial difference and the structural character of racism and instead champions individual qualities and entertainment. In reality, however, numerous studies show that racism, in whatever form it may 
take, is still firmly entrenched in British sport. The quest to tackle the myth of the natural black athlete, as was the goal of Carrington and McDonald over a decade ago, remains an ongoing battle (Carrington and McDonald 2001). There may be some reason for optimism though, as some respondents were aware of and opposed the racism that resides in the institutions of modern football. These findings might be indicative of a more conscious awareness among fans (Cleland and Cashmore 2013). Respondents were also equally aware that the sport media are a huge business and often called out the media on their exaggerations. It might prove a potent gateway to educate viewers on how (subtle) forms of racism and stereotyping maintain the status quo.

In the case of gender, more heterogeneous discourses were identified. A considerable portion of the respondents, most of them (though not all) women, presented a negotiated/ oppositional reading of women's football which they considered a truer appropriation of the game. These alternative discourses also function as reminders that cultural texts don't exist in a vacuum, but that readings of these texts are interspersed by a variety of external factors (Morley 1980, 1983). A few female students that were actively involved in the women's game used their own personal experiences to provide a very different account of women's football than the one appropriated by the mass media. With the growing popularity of women's football, one might expect that such discourses become more prevalent.

Differences between black or white students were more difficult to single out, although black (male) students were in some instances more eager to draw on oppositional/negotiated readings regarding gender and race in football. However, it does illuminate one of the limitations of the study, it being the specific conceptualization of race. Labelling the students predominantly as either black or white on the basis of their own (brief and sometimes not too explicit) textual introduction, isn't entirely without its pitfalls. Most notably, this conceptualization may sidestep other forms of belonging such as those at the national or local level and proves problematic with the idea of mixed people. The use of these same categories in the topics and questions that were asked during the interviews may also have structured the way respondents use certain discourses although they were free to add their own viewpoints. We suggest, therefore, that future audience research aims to produce a fuller understanding of a participant's sense of belonging that includes various domains of social experience such as national and/or local belongings. This would require a vastly more complex approach in both the focus of the interviews as well as in the analysis of the data and presents the researcher with new and politically infused questions about groupings and racial hierarchies in and through (mediated) football.

\section{Notes}

1. The term 'physicality discourse' and terms like 'economic disocurse' or 'cultural disocurse' used later on in this section derive from Van Sterkenburg \& Knoppers (2004).

2. The ages of five respondents are unknown, but all fall well within the aforementioned range.

3. Andy Gray is a former Sky Sports commentator who was fired in 2011 after he made derogatory, sexist remarks about a female linesman and towards his female co-presenter.

\section{Acknowledgements}

We appreciate the support we received from Brunel University and Croydon College for conducting the interviews, especially Dr. Laura Hills, Dr.Eileen Kennedy and Dr. Alison Mailtand. We also 
appreciate the support from UEFA as the study has been made possible as part of the UEFA Grant Scheme and has been presented to UEFA (Van Sterkenburg, 2013). Each year, the European Football Association UEFA awards several scholars worldwide to conduct independent research through its UEFA Grant Scheme.

\section{Disclosure statement}

No potential conflict of interest was reported by the authors.

\section{References}

Adams, C., M. Ashton, H. Lupton, and H. Pollack. 2014. "Sport is King: An Investigation into Local Media Coverage of Women's Sport in the UK East Midlands." Journal of Gender Studies 23 (4): 422-439.

Alabarces, P., A. Tomlinson, and C. Young. 2001. "Argentina versus England at the France ' 98 World Cup: Narratives of Nation and the Mythologizing of the Popular." Media, Culture \& Society 36 (1): 547-566.

Billings, A. C., and H. L. Hundley. 2010. "Examining Identity in Sports Media." In Examining Identity in Sports Media, edited by A. C. Billings and H. L. Hundley, 1-16. Thousand Oaks, CA: Sage.

Boeije, H. 2010. Analysis in Qualitative Research. London: Sage.

Bonilla-Silva, E., and D. Dietrich. 2011. "The Sweet Enchantment of Color-blind Racism in Obamerica." The ANNALS of the American Academy of Political and Social Science 634 (1): 190-206.

Bruce, T. 1998. "Audience Frustration and Pleasure: Women Viewers Confront Televised Women's Basketball." Journal of Sport and Social Issues 22 (4): 373-397.

Bruce, T. 2011. "Shifting the Boundaries: Sportswomen in the Media." In Communication on the Edge: Proceedings of the 2011 Australia and New Zealand Communication Association Conference, edited by A. Henderson, 1-16. Hamilton: Australian and New Zealand Communication Association.

Bruce, T. 2013. "Reflections on Communication and Sport: On Women and Femininities." Communication and Sport 1 (1-2): 125-137.

De Bruycker, G. 2012. “Zwarte Parels: Een inhoudsanalyse naar het gebruik van raciale stereotypen in Belgische sportkranten [Black Pearls: A Content Analysis regarding the Use of Racial Stereotypes in Belgian Sport Newspapers]." PhD diss., University of Ghent.

Burdsey, D. 2006. "No Ball Games Allowed? A Socio-historical Examination of the Development and Social Significance of British Asian Football Clubs." Journal of Ethnic and Migration Studies 32 (3): 477-496.

Carrington, B. 2011. “'What I Said Was Racist - But I'm Not a Racist': Anti-racism and the White Sports/Media Complex.” In Sport and Challenges to Racism, edited by J. Long and K. Spracklen, 83-99. Basingstoke: Palgrave Macmillan.

Carrington, B., and I. McDonald. 2001. "Introduction: 'Race', Sport and British Society." In "Race", Sport, and British Society, edited by B. Carrington and I. McDonald, 1-26. London: Routledge.

Caudwell, J. 2011. "Reviewing UK Football Cultures: Continuing with Gender Analyses." Soccer \& Society 12 (3): 323-329.

Cleland, J., and E. Cashmore. 2013. "Fans, Racism and British Football in the Twenty-first Century: The Existence of a 'Colour-blind' Ideology." Journal of Ethnic and Migration Studies 40 (4): 638-654.

Coakley, J. 2009. Sports in Society: Issues and Controversies. Boston, MA: McGraw-Hill.

Conlan, T. 2012. "Olympics and Euro 2012 Triumph over Downton and X Factor to Win TV Gold." The Guardian December 12, 16.

Cooky, C., M. A. Messner, and R. H. Hextrum. 2013. "Women Play Sport, but Not on TV: A Longitudinal Study of Televised News Media." Communication \& Sport 1 (3): 203-230.

van Dijk, T. A. 2009. Society and Discourse: How Social Contexts Influence Text and Talk. Cambridge: Cambridge University Press.

Gibson, O. 2013. "Premier League Still 'Quintessentially English', Says Richard Scudamore.” The Guardian, November 19. Accessed January 24, 2014. www.theguardian.com/football/2013/nov/19/ premier-league-english-richard-scudamore 
Gunaratnam, Y. 2003. Researching 'Race' and Ethnicity: Methods, Knowledge and Power. London: Sage. Hall, S. (1980) 2005. “Encoding/Decoding." In Culture, Media, Language: Working Papers in Cultural Studies 1972-79, edited by S. Hall, D. Hobson, A. Lowe, and P. Willis, 117-127. Reprint, London: Routledge.

Hall, S. 1995. "The West and the Rest: Discourse and Power." In Formations of Modernity, edited by S. Hall and B. Gieben, 275-332. Cambridge: Blackwell.

Hall, S. 1997. “The Spectacle of the 'Other"' In Representation: Cultural Representations and Signifying Practices, edited by S. Hall, 223-290. London: Sage.

Hall, S. 2011. "The Whites of Their Eyes: Racist Ideologies and the Media." In Gender, Race, and Class in Media: A Critical Reader, edited by G. Dines and J. M. Humez, 81-84. Thousand Oaks, CA: Sage.

Harrison, C. K., S. M. Lawrence, and S. J. Bukstein. 2011. "White College Students' Explanations of White (and Black) Athletic Performance: A Qualitative Investigation of White College Students." Sociology of Sport Journal 28 (3): 347-361.

Hermes, J. 2005. "Burnt Orange: Television, Football, and the Representation of Ethnicity." Television \& New Media 6: 49-69.

Hylton, K. 2009. 'Race' and Sport: Critical Race Theory. Abingdon: Routledge.

Kane, M. J. 2013. "The Better Sportswomen Get, the More the Media Ignore Them." Communication \& Sport,1-6. Advance Online Publication. doi:10.1177/2167479513484579.

Kane, M. J., N. M. LaVoi, and J. S. Fink. 2013. “Exploring Elite Female Athletes' Interpretations of Sport Media Images: A Window into the Construction of Social Identity and 'Selling Sex' in Women's Sports." Communication \& Sport 1 (3): 269-298.

Knoppers, A., and A. Elling. 2001. Gender, Etniciteit en de sportmedia: productieprocessen en publieksinterpretaties [Gender, Ethnicity and the Sportmedia: Production Processes and Public Interpretations]. Arnhem: NOC`NSF Breedtesport.

Lechner, F. J. 2007. "Imagined Communities in the Global Game: Soccer and Development of Dutch National Identity." Global Networks 7 (2): 215-229.

Ličen, S., and A. C. Billings. 2013. "Cheering for 'Our' Champs by Watching Sexy Female Throwers: Representation of Nationality and Gender in Slovenian 2008 Summer Olympic Television Coverage." European Journal of Communication 28 (4): 379-396.

Lines, G. 2000. "Media Sport Audiences - Young People and the Summer of Sport '96: Revisiting Frameworks for Analysis." Media, Culture and Society 22 (5): 669-680.

McCarthy, D., R. L. Jones, and P. Potrac. 2003. "Constructing Images and Interpreting Realities: The Case of the Black Soccer Player on Television." International Review for the Sociology of Sport 38 (2): $217-238$.

Morley, D. (1980) 2005. “Texts, Readers, Subjects.” In Culture, Media, Language: Working Papers in Cultural Studies 1972-79, edited by S. Hall, D. Hobson, A. Lowe, and P. Willis, 154-165. Reprint London: Routledge.

Morley, D. 1983. "Cultural Transformations: The Politics of Resistance." In Language, Image, Media, edited by H. H. David and P. Walton, 104-117. Oxford: Basil Blackwell.

Morning, A. 2009. "Toward a Sociology of Racial Conceptualization for the 21st Century." Social Forces 87: 1167-1192.

Peeters, R. 2013. "I don't see different colors, different races. I just see eleven people on a pitch". How British students assign meaning to race/ethnicity and gender in mediated sports. MA Thesis, Utrecht University, The Netherlands.

Pfister, G. 2010. "Women in Sport - Gender Relations and Future Perspectives." Sport in Society 13 (2): 234-248.

Pressland, A. 2012. “'Still Struggling after All These Years?' the Representation of Sportswomen in Middle-brow British Newspapers 2008-2009.” PhD diss., University of York.

Schönwälder, K. 2010. "Beyond the Race Relations Model: Old Patterns and New Trends in Britain.” In National Paradigms in Migration Research, edited by D. Thränhardt and M. Bommes, 109-126. Osnabrück: V\&R Unipress GmbH.

Strauss, A., and J. Corbin. 1998. Basics of Qualitative Research: Techniques and Procedures for Developing Grounded Theory. Thousand Oaks, CA: Sage. 
Van Sterkenburg, J. 2013. Race/ethnicity, gender and audience receptions of football on television in the Netherlands and England. A research project financially supported by the UEFA Grant Scheme, for internal use UEFA. Nyon: UEFA.

Van Sterkenburg, J., \& Knoppers, A. 2004. Dominant discourses about race/ethnicity and gender in sport practice and performance. International Review for the Sociology of Sport, 39, 301-321.

Women's Sport and Fitness Foundation. 2012. Football Factsheet. London: Women's Sport and Fitness Foundation. 